\title{
Cidade como metáfora de si: representação socioespacial de Cuiabá-MT segundo a criança
}

\section{City as a metaphor of itself: sociospatial representation of Cuiabá-MT, according to the child}

\begin{abstract}
Eliza M. P. da Silva ${ }^{[a]}$, Daniela B. da S. F. Andrade ${ }^{[b]}$
[a] Mestre em Educação pela Universidade Federal de Mato Grosso (UFMT), membro do Grupo de Pesquisa em Psicologia da Infância (GPPIN), Cuiabá, MT - Brasil, e-mail: elizamoura@outlook.com

[b] Professora Adjunta da Universidade Federal de Mato Grosso (UFMT), Curso de Psicologia, Programa de Pós-Graduação em Educação, Coordenadora do Grupo de Pesquisa em Psicologia da Infância (GPPIN), Cuiabá, MT - Brasil, e-mail: freire.d@terra.com.br
\end{abstract}

\section{Resumo}

Este artigo propõe uma discussão sobre a relação da criança com a cidade, mediante análise compreensiva do discurso associado ao mapa da cidade construído pela criança participante, com o objetivo de refletir sobre aspectos de sua constituição identitária nessa relação. $A$ análise das significações se orienta pela articulação entre a Teoria Histórico-Cultural (VIGOTSKI, 2009, 2010) e a Teoria das Representações Sociais (MOSCOVICI, 2003), esta última no diálogo com os estudos de Jodelet $(1982,2001)$. Os estudos de Tuan $(1980,1983)$ sobre a noção de lugar, topofilia e topofobia também integram o referencial teórico, que, em seu conjunto, possibilita compreender a relação entre criança e cidade como aspecto importante para o desenvolvimento infantil. O procedimento metodológico adotado para a apreensão da 
representação socioespacial deu-se pelo recolhimento do desenho da cidade, inspirado na proposta dos mapas cognitivos (ALBA, 2011), acompanhado de entrevista semiestruturada com uma criança de uma escola municipal de Educação Básica de Cuiabá, MT. A análise da entrevista e do mapa da cidade orientou-se pela perspectiva compreensiva do discurso e revelou que a representação socioespacial da cidade de Cuiabá é influenciada por valores, vivências e afetos da criança, estando presentes elementos de suas particularidades, mas que também são frutos de relações estabelecidas socialmente. Além disso, nota-se que os lugares do afeto permeiam o processo de formação identitária da criança, aspecto que permite anunciar que, em alguma medida, a cidade é tomada como metáfora de si.

Palavras-chave: Representação socioespacial. Cidade. Mapa cognitivo. Infância.

\section{Abstract}

This article proposes a discussion about the relationship between child and the city, by comprehensive analysis of speech associated to the city map built by the participant child, with the objective of reflection about aspects of its identity constitution in this relationship. The analyses of significances is oriented by the articulation between the Theory of CulturalHistory (VIGOTSKI, 2009, 2010) and the Theory of Social Representations (MOSCOVICI, 2003), this one in the dialogue with the studies of Jodelet (1982, 2001). The studies of Tuan (1980, 1983), about the notion of place, topofilia and topofobia also integrates the theorical reference that, in its group, makes possible to comprehend the relationship between child and city as an important aspect of the infantile development. The adopted methodological procedures to the seizure of sociospatial representation happened by the collection of the city drawing, inspired in the proposal of cognitive maps (ALBA, 2011), followed by semi-structured interview with a child of one municipal school of Basic Education of Cuiabá, MT. The analysis of the interview and the city map was oriented by the comprehensive perspective of the speech and it revealed that sociospatial representation of the city of Cuiabá is influenced by values, experiences and the child's affection, there being elements of its particularities, but that are also results of socially established relations. Furthermore, it is noticed that affection places permeate the process of the child's identity formation, aspect that allows announcing that, in some amount, the city is taken as a metaphor of itself.

Keywords: Sociospatial representation. City. Cognitive map. Childhood. 


\section{Introdução: a cidade e a criança}

Este artigo discute a relação da criança com a cidade, mediante análise compreensiva do discurso associado ao mapa da cidade construído por uma das crianças participantes. Objetiva-se compreender as significações dessa criança a respeito da cidade, bem como refletir, no âmbito dessa relação, sobre aspectos de sua constituição identitária.

A análise das significações se orienta pela articulação entre a Teoria Histórico-Cultural (VIGOTSKI, 2009, 2010) e a Teoria das Representações Sociais (MOSCOVICI, 2003), esta no diálogo com os estudos de Jodelet (1982, 2001), sobre os Mapas Sociais de Paris. Os estudos de Tuan $(1980,1983)$ sobre a noção de lugar, topofilia e topofobia também integram o referencial teórico, que, em seu conjunto, possibilita compreender a relação entre a criança e a cidade como aspecto importante para o desenvolvimento infantil.

A adoção da criança como sujeito de pesquisa se pauta na proposta da Sociologia da Infância, por meio do conceito de criança sociológica (JAMES; JENKS; PROUT, 2005), a qual a entende como ator social, que constrói sua identidade e sua condição cidadã nas relações sociais, em contato com os conhecimentos que circulam em seu entorno. Tal entendimento se distancia das representações "adultocêntricas", a qual a considera como ser que ainda não é, mas que virá a ser, e surge com o propósito de contribuir com os movimentos que buscam dar visibilidade social à infância, destacando-se sua visibilidade científica e cívica.

A cidade é considerada um espaço social, essencialmente dotado de significados, e, por sua dimensão simbólica, histórica e socialmente construída, transforma-se em referencial identitário para a criança, podendo ser entendida como objeto de representação social (JODELET, 1982) presente e atuante na constituição subjetiva da criança. Dessa forma, a relação da criança com a cidade é pensada na perspectiva da importância do espaço ou meio social, tanto para o desenvolvimento humano quanto para a construção do conhecimento social. 


\section{Teoria Histórico-Cultural e Teoria das Representações Sociais}

A Teoria Histórico-Cultural de Vigotski (2009, 2010) entende o desenvolvimento humano por meio da Lei Geral do Desenvolvimento Cultural, que destaca a importância da dimensão social, das relações entre pares e com a própria cultura que inclui o espaço (ou meio). Este último é essencialmente dotado de significados construídos nas relações entre pares e com o próprio espaço, o que permite pensá-lo como possibilidade, atuante (ou não) no desenvolvimento da personalidade consciente, na medida de sua relação com a criança em dada etapa desse desenvolvimento - ou seja, com base no conceito de vivência, que significa a unidade da personalidade da pessoa com as particularidades do meio, da forma como está representada no desenvolvimento (VIGOTSKI, 2010).

Para o autor (2009), todas as relações são mediadas por duas atividades humanas essenciais, a de reprodução e a de criação, que, ao contrário da primeira, pode ser definida como toda a atividade que resulta na criação de novas imagens ou ações, sem reproduzir impressões e ações da sua experiência anterior. Atrelado a esta última, tem-se o conceito de reelaboração criativa (VIGOTSKI, 2009), que confere à criança o potencial criativo de significação do seu entorno social, possibilitando considerá-la como sujeito ativo em seu próprio desenvolvimento, capaz de ampliar suas possibilidades de atuação, a partir do próprio contato com o meio em que vive. Em face do exposto, tem-se que a apropriação da cultura pela criança não segue a lógica de uma internalização passiva, ao contrário, considera que as crianças se apropriam da cultura, dos significados, das regras e dos costumes de seu meio social, mas, por meio da significação de suas vivências, permeadas pela reelaboração criativa, atribuem sentido ao mundo cultural em que estão inseridas. Assim, a constituição subjetiva das crianças acontece mediante suas vivências, que carregam significações e interpretações pessoais mas também são permeadas pelo arcabouço simbólico construído no e pelo meio sociocultural.

Esse arcabouço simbólico do meio sociocultural possibilita pensar as significações infantis pelo viés da Psicologia Social, com base na 
Teoria das Representações Sociais (MOSCOVICI, 2003; JODELET, 1982, 2001), que, em linhas gerais, entende as representações sociais como um conjunto de saberes práticos partilhados pelos indivíduos em seus grupos de pertença, originados na vida cotidiana, no curso das comunicações interpessoais, podendo ser também denominadas de senso comum. Jodelet (2001) considera que a representação se encontra em uma relação de simbolização e de interpretação com determinado objeto (a princípio desconhecido) de natureza social, material ou ideal. Isso quer dizer que o sujeito, ao simbolizar um objeto, constrói a representação que se coloca em seu lugar, fazendo presente o que está ausente. Por sua vez, ao interpretá-lo, o mesmo sujeito confere-lhe significado.

Com essa proposta, entende-se que o ser humano, na qualidade de ser social ligado a grupos de pertença, apropria-se da realidade a partir do que é constituído na sociedade, mas também participa de sua constituição, construindo representações mediante sua elaboração psicológica e social. Disso entende-se que as representações "são socialmente valoradas e utilizadas numa construção ativa pelo sujeito social em função das suas metas e das significações sociais de que o meio urbano é portador" (JODELET, 1982, p. 7).

A ideia do meio urbano como portador de significações sociais exemplifica o espaço como de ordem social, tornando possível considerar que, além de ser objeto de representação, o espaço também adquire papel importante na constituição da identidade pessoal e social, a partir da identidade dos lugares, trazendo um elemento de bem-estar ao indivíduo que, por meio da identificação com o lugar, compensa as ameaças e os medos externos (JODELET, 2002). Essa noção de identidade dos lugares dialoga com o conceito de lugar criado por Tuan (1980, 1983), que define que o espaço se transforma em lugar à medida que é dotado de valor. $\mathrm{Na}$ mesma direção, o conceito de topofilia significa o elo de afeto entre a pessoa e o lugar (TUAN, 1980), que, por sua vez, refere-se à ideia de que o ser humano estabelece vínculo afetivo, no sentido do bem-estar, associado à dimensão simbólica, histórica e social do lugar. Em contrapartida, a topofobia refere-se aos sentimentos negativos de medo, angústia, mal-estar, também associados aos lugares. 
Finalmente, ao propor uma investigação com crianças, destaca-se o diálogo da Teoria das Representações Sociais com a infância, com base na proposta de Castorina e Kaplan (2003), que destacam que o processo de construção do conhecimento da criança não é direto e passivo, uma vez que a transmissão social é ressignificada e reelaborada pela criança. A criança significa seu contexto social por meio de suas vivências e também por meio da apropriação das representações sociais, de modo que ambas as perspectivas, da Teoria Histórico-Cultural e da Teoria das Representações Sociais, consideram a relação recíproca entre sujeito e sociedade e compreendem a importância da dimensão social na construção do conhecimento, bem como o papel do sujeito na reelaboração deste. É nesse sentido que o presente estudo pensa as representações sociais na infância e propõe uma investigação com base em seus discursos.

\section{Perspectiva metodológica que aproximou criança e cidade}

A apreensão da representação socioespacial deu-se pela recolha do desenho da cidade, inspirada na proposta dos mapas cognitivos (ALBA, 2011), acompanhada de entrevista semiestruturada com uma criança de uma escola municipal de Educação Básica de Cuiabá, MT. Os critérios para a seleção da participante foi: idade entre 9 e 12 anos, estudante do quinto ano do Ensino Fundamental, desejo de participar da pesquisa e autorização do responsável mediante assinatura do termo de consentimento livre e esclarecido ${ }^{1}$. A análise da entrevista e do mapa da cidade orientou-se pela perspectiva compreensiva do discurso e seguiu o roteiro de entrevista organizado em três etapas: Contextualização; Nomeação, classificação e significação dos lugares; Informação, análise e crítica.

1 O termo de consentimento livre e esclarecido destinado à criança também foi assinado por cada participante, como garantia do desejo de participar da pesquisa. 


\section{A cidade como metáfora de si: análise da representação socioespacial}

\section{I - Contextualização}

Lívia² $^{2}$ de 10 anos, nasceu em Cuiabá, mora no bairro Alvorada (região $\mathrm{CPA}$ ) com sua mãe, seu pai e seus dois irmãos, e sua entrevista teve duração de 30 minutos e 35 segundos. A menina afirmou ir à escola sozinha e a pé, acrescentando que, às vezes, faz o trajeto acompanhada de suas amigas. Brincar e assistir à televisão são as atividades de seu agrado quando não está na escola.

Ao ser questionada sobre onde costuma ir quando não está em casa, Lívia responde:

Pizzarias, churrascarias, ir à igreja e para a casa dos meus avós. Às vezes, eu tenho que brincar com os meus irmãos... Às vezes, eu tenho que brincar com os meus primos quando eu vou para a casa dos meus avós...

A repetição do verbo ter no presente do indicativo associado ao momento da brincadeira, "tenho que brincar com meus irmãos e tenho que brincar com os meus primos", permite pensar que a companhia dos irmãos e primos não é a preferência de Lívia, que optaria pelos amigos se lhe fosse possível escolher.

Partindo para a pergunta "Você já saiu de casa sozinha?", Lívia responde positivamente e explica:

Para ir para os ensaios da igreja, para o ensaio de músicas, de violino, para ir para a casa dos meus avós também, porque é muito perto da minha... E a escola. Ontem mesmo eu fui para casa de meus avós... É... Eu fui para igreja ontem também sozinha.

2 De uma amostra de 40 crianças, para efeito deste texto, destacou-se o material produzido por Lívia, nome fictício. 
Diante da pergunta sobre o motivo pelo qual sai sozinha, Lívia revela aspectos de sua relação com a mãe:

Porque minha mãe não tem tempo, tipo assim, de me levar até onde ela está. Ela trabalha muito, então eu tenho que ir só. Até ela chegar, então vai atrapalhar muito.

A criança percebe que sua dependência de locomoção em relação à mãe pode atrapalhá-la, visto que ela trabalha muito, e por isso revela que o seu sair sozinha está mais relacionado a um sentido de necessidade do que uma opção de seu agrado, ou mesmo um anseio por mobilidade mais autônoma.

No entanto, quando Lívia afirma que gosta de sair sozinha e explica o motivo, entende-se melhor o sentido do seu sair sozinha:

Porque assim eu fico um pouco longe dos meus irmãos, porque tudo que eu faço eu tenho que estar perto dos meus irmãos, eu tenho que estar junto. Então, por isso que eu gosto de sair um pouco sozinha.

Para Lívia, sair sozinha é uma necessidade, porque sua mãe não tem condições de levá-la, mas ao contrário do que a princípio se pensou, para ela esse momento se torna agradável, uma vez que tem a oportunidade de ficar distante de seus irmãos, que estão sempre por perto. Isso, por sua vez, reforça a ideia de que "os irmãos" não são as companhias preferidas de Lívia para o momento da brincadeira.

Ao ser questionada sobre os lugares aonde vai quando sai sozinha, a menina responde: "Para a casa dos meus avós, para a escola e para a aula de violino". A casa dos avós aparece pela terceira vez na fala de Lívia, indicando que, além de ser um lugar próximo à sua casa, é também muito presente em sua vida e de modo semelhante à aula de violino, que aparece pela segunda vez em sua fala.

Seguindo com a conversa, pergunta-se "Você já pensou nos lugares de Cuiabá que você conhece?", e Lívia cita alguns: 
Casa do Artesão, Parque Mãe Bonifácia, Museu do Rio, a Coca-Cola com o meu pai sempre eu vou e o SESC Arsenal, sempre estou lá fazendo passeios. A Igreja Assembleia. A casa dos meus avós, o salão da minha mãe, que às vezes eu vou também.

Além da casa dos avós, a igreja se destaca pela quarta aparição na fala da menina, indicando ser esse outro lugar importante em sua vida. $\mathrm{O}$ SESC Arsenal também ganha destaque ao ser acompanhado pela fala "sempre estou lá fazendo passeios", ou seja, por ser um lugar que Lívia vai com frequência e por estar relacionado ao passeio e, portanto, a algo prazeroso. Enfim, a casa dos avós, a igreja e o SESC Arsenal aparecem como lugares de destaque.

\section{II - Nomeação, classificação e significação dos lugares}

Antes do início dessa etapa, foi solicitado a Lívia um desenho do mapa da cidade de Cuiabá, de maneira que a conversa seguinte foi direcionada para a exploração do desenho e para a explicação sobre os lugares apresentados e as sugestões sobre o que as pessoas poderiam pensar ou sentir quando estivessem em tais lugares.

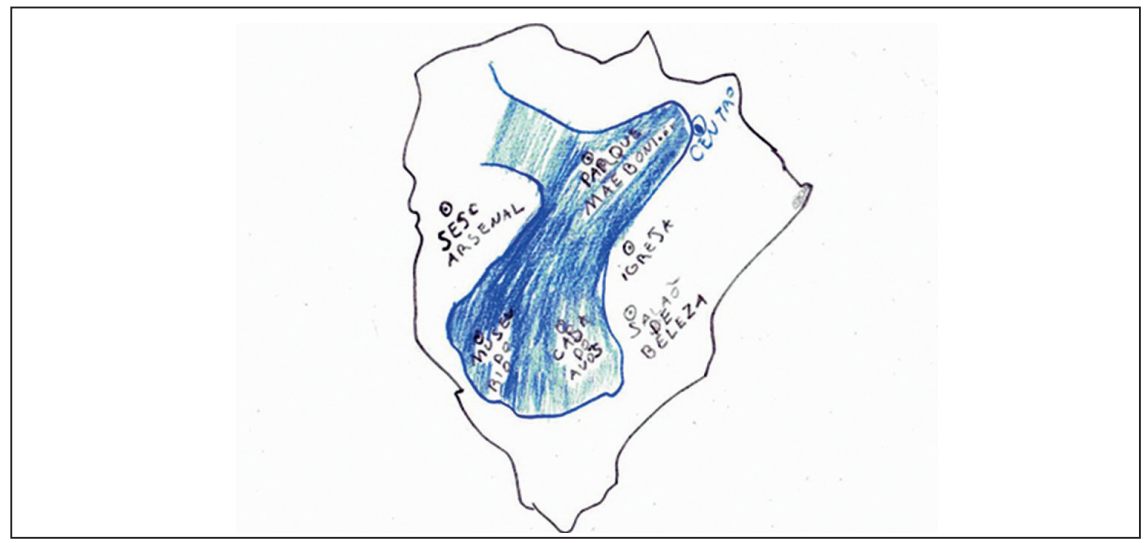

Figura 1 - 0 mapa de Cuiabá desenhado por Lívia

Fonte: Dados da pesquisa. 
O mapa de Lívia confirma a importância da casa dos avós, da igreja e do SESC Arsenal, mas também apresenta outros lugares que a menina diz frequentar, como Museu do Rio, Parque Mãe Bonifácia, Salão de Beleza, Centro da cidade e o Rio Cuiabá3. Ao responder à pergunta "Que lugares são esses?", a menina fala um pouco sobre eles:

Lívia: O SESC Arsenal é onde ficam vários, assim, ficam vários cursos, dão vários cursos lá. O Parque Mãe Bonifácia é onde as pessoas ficam à tarde, assim, tipo ao ar livre, e o Museu do Rio é onde fica um museu cheio de peixes. Tem uma escada, aí a agente vai subir lá e ver as coisas do alto, e tem um aquário. E a casa dos meus avós fica bem aqui próximo. É bem legal, porque tem os meus primos, quando a minha prima vai ficar... Mais legais. O salão de beleza fica um monte de mulheres, só que quando os meus irmãos vão para a escola e o meu pai não está em casa, eu vou para lá. E a igreja é aonde eu vou, para fazer os ensaios de música e onde eu vou para cantar e orar.

Pesquisador: $O$ que se faz nesses lugares?

Lívia: No SESC Arsenal, eu e a minha mãe, a gente já fez cursos lá; no Parque Mãe Bonifácia, eu já cai de bicicleta; no Museu do Rio a gente foi lá semana passada, mas estava fechado. E eu fui para a escola e também estava fechado, porque está fazendo reforma. Na igreja eu fui ontem. Na casa dos meus avós eu fui ontem também, eu fui lá pegar um negócio para a minha mãe; e no salão de beleza da minha mãe eu fui ontem à noite também.

Esse depoimento revela três aspectos importantes da relação de Lívia com os lugares da cidade. O primeiro diz respeito ao SESC Arsenal, que representa para a menina um lugar de possibilidades, de oportunidades de crescimento pelos vários cursos que oferece, um lugar a que Lívia vai com frequência, assim como a igreja aonde vai para orar, cantar e realizar os ensaios de música.

3 A cor azul, com que a criança desenhou o Centro e o Rio Cuiabá, é aleatória e sinaliza que os lugares foram inseridos em outro momento da entrevista, após a primeira solicitação do desenho do mapa da cidade. 
O segundo aspecto está relacionado à importância da casa dos avós, que se confirma como um lugar pelo qual a criança nutre sentimento de topofilia, que é "bem legal", possivelmente pela presença da prima, revelando, mais uma vez, que o afeto para com os lugares tem ligação com o afeto entre as pessoas que neles convivem. O terceiro aspecto que chama atenção é o modo como Lívia fala do Parque Mãe Bonifácia, como um lugar onde se pode ficar ao ar livre, associando-o ao bem-estar e também ao movimento, à aventura e aos riscos inerentes, visto que lá a menina caiu de bicicleta.

Avançando para a pergunta "Quando as pessoas estão nesses lugares, o que elas devem pensar?", Lívia apresenta aspectos negativos da relação com a cidade, que se relacionam a vivências de situações desagradáveis:

Pensar em não jogar lixo no chão, para, tipo assim, não sujar o meio ambiente, porque a gente mesmo suja. É... Pensar em não maltratar os outros... Porque eu só caí porque jogaram bola de propósito. E... Em não bater, porque já teve várias brigas no meio da rua e na frente do SESC Arsenal e daí magoou as pessoas. Porque as pessoas saem do curso, elas esquecem, porque vão frequentar e brigam. Eu não gosto de briga nem falsidade. Eu não gosto.

Lívia se incomoda muito com os desentendimentos entre as pessoas e fala da vivência desagradável de quando caiu porque lançaram a bola contra ela propositalmente. Além disso, ela diz que as brigas magoam as pessoas, provavelmente porque estas também lhe magoam. Seguindo a conversa, quando lhe perguntam "O que as pessoas sentem quando estão nesses lugares?", Lívia responde:

Lívia: As pessoas sentem alegria, sentem orgulho de estar lá. Sentem alegria, porque às vezes... Porque eu e a minha família não temos união, ébriga de lá, é briga de cá. Não temos. Então, aí quando a gente vai lá, a gente se sente unido, a gente sente uma alegria. 
Pesquisador: Lá onde?

Lívia: Lá no SESC Arsenal, no Museu do Rio... Até, às vezes, na casa dos meus avós, no Parque Mãe Bonifácia.

Pesquisador: Sentem-se unidos?

Lívia: Alegria, unidas. Eles sentem um ar livre, lá se sentem juntas.

Esse depoimento revela que as brigas e a desunião são aspectos da relação familiar que incomodam a menina e que são amenizados em lugares como o SESC Arsenal, o Museu do Rio e o Parque Mãe Bonifácia, que, por essa razão, se tornam do afeto de Lívia, lugares pelos quais ela nutre sentimentos topofílicos.

Ao se mudar um pouco a pergunta para "O que você pensa?", Lívia destaca um lugar até então não mencionado, o Rio Cuiabá:

Lívia: Eu penso... Ah! Que eu vou prosperar, que tipo assim, às vezes, eu posso ser até dono deste lugar. Isso que eu sinto.

Pesquisador: O quê?

Lívia: Ser dono desse lugar, porque muitas pessoas sentem assim. Quando a gente vai no Museu do Rio sempre o meu pai fala: "A gente vai no rio, porque atravessando a rua tem um rio". Aí, a gente...

Pesquisador: Qual rio?

Lívia: O Rio Cuiabá. Aí, a gente fala assim que... A gente fala assim... Sempre o meu irmão fala que ele vai entrar dentro do rio para pegar um jacaré e mostrar para a minha irmã. Sempre ele fala.

Nesse momento, devido à menção ao Rio Cuiabá, perguntou-se à criança se ela gostaria de desenhá-lo em seu mapa, e ela respondeu positivamente, desenhando-o de maneira a permear os lugares anteriormente desenhados, como mostra o mapa da Figura 1. Para concluir essa etapa, perguntou-se “O que você sente quando está nesses lugares?”, e Lívia reforça seu grande anseio pela união da família: "União, igual eu falei...", "União, alegria e prosperidade. Porque se a gente for neste lugar, a gente vai se unir, unir, unir". Assim, considerando essa fala, bem como o mapa da cidade, 
nota-se a presença de lugares que se tornam de afeto porque representam a possibilidade de união com a família.

Na perspectiva de Lívia, a identidade dos lugares se constitui na relação com a identidade da criança e de seu grupo familiar, em um exercício projetivo, no qual a menina apresenta-se esperançosa com a possibilidade de superação dos problemas familiares, levando em consideração a relação com as propriedades dos lugares (ar livre), seu impacto no humor de seus familiares e, consequentemente, nas relações maior união.

\section{III - Informação, análise e crítica}

Nessa última fase, foram feitas perguntas em relação à cidade como um todo, e, ao ser questionada sobre o que sentia por Cuiabá, Lívia respondeu:

Eu sinto alegria, porque quando a gente estava morando em Sinop, a gente passou por muita prova. Eu morei em Sinop mais ou menos uns três anos e ali a gente foi uma união, mas quando chegou aqui foi só briga, briga, briga... Não tem união com a minha família. É... Tipo assim, minha mãe compra um negócio para mim e o meu irmão quer. Aí, eu tenho que pegar e dar. Por isso eu não tenho união com a minha família. Eu sinto alegria e menos união. Amor e alegria, menos união.

Nessa fala é que se compreende melhor o teor das brigas e dos conflitos familiares até então não especificados pela menina. A falta de união da família, tão reforçada anteriormente, parece ter íntima ligação com a relação dela com os irmãos, e isso fica ainda mais evidente diante das questões que se seguem na conversa:

Pesquisador: Quando você pensa em Cuiabá, do que você se lembra?

Lívia: Da minha infância e... Da minha infância e... Momentos... Momentos, momentos.

Pesquisador: Disso que vocêlembrou, qual você acha que émais importante? Lívia: Minha infância. 
Pesquisador: Por quê?

Lívia: Porque a minha infância foi... Porque a minha irmã só foi nascer quando eu tinha de sete para cinco anos... Cinco para seis anos... Não sei se foi sete, assim... Aí, a minha irmã nasceu. E daí... E já sofreu, então...

Pesquisador: Sofreu?

Lívia: Sofri.

Pesquisador: Por quê?

Lívia: Porque a minha irmã era assim. Tudo o que eu tinha, ela queria. Então, eu tinha que dar, eu era obrigada a dar.

Pesquisador: Por quê?

Lívia: Porque se eu não desse, a minha mãe brigava comigo. E a minha irmã chorava muito, muito, muito. E ela dormia no mesmo quarto que eu. E eu nunca tive, tipo assim, um quarto próprio, eu nunca tive valorização pelo meu pai e pela a minha mãe. Eles, na verdade, nunca tiveram por mim.

Pesquisador: Não tiveram o quê?

Lívia: Valorização.

Pesquisador: Eles não valorizam você?

Lívia: Não.

Pesquisador: Por quê?

Lívia: Ai! Eu não consigo explicar... Essa valorização que eles não têm.

Percebe-se que os conflitos familiares de que antes se falava parecem corresponder à relação da criança com os irmãos mais novos que, como em muitos casos, é permeada por brigas e disputas comuns entre crianças que convivem e dividem as coisas. No que se refere à valorização citada por Lívia, pode-se pensar que ela, por ser a mais velha, acaba sendo a mais cobrada pelos pais, tendo que ceder em muitos casos e, portanto, ceder muito mais que os irmãos mais novos, em especial a irmã com a qual divide o quarto.

Essas vivências no contexto privado da vida familiar assumem a condição de conflito e tensão interna, e, provavelmente por essa razão, o passeio pelos lugares da cidade são descritos com destaque para 
as sensações, como ar livre, alívio e alegria. Nessa perspectiva, a relação da menina com a cidade se associa ao sentido de liberdade, relaxamento e descanso que compensa os conflitos originados na relação com os irmãos mais novos.

Seguindo com a pergunta "Como você se sente quando anda nas ruas de Cuiabá?", Lívia reforça essa ideia dizendo: "Eu sinto assim um ar livre, um amor, uma união... Eu sinto cheio de valorização por Cuiabá, eu sinto alegria". Essa declaração revela que, diante do prazer que sente quando passeia pelos lugares da cidade, Lívia parece projetar a valorização que gostaria que seus pais tivessem por ela em Cuiabá, fazendo desta um lugar de pertencimento. Essa relação entre a identidade do lugar (cidade como um todo) e a identidade individual (da criança) permeia as vivências de Lívia e, portanto, sua construção subjetiva, de maneira que a sua valorização por Cuiabá torna-se fundamental ao representar a base na qual ela encontra força para a valorização de si mesma. A cidade como metáfora de si - esse parece ter sido o exercício que Lívia apresenta para comunicar a necessidade de se sentir valorizada pela família, ter seu lugar assegurado como filha e como ser de possibilidades.

Seguem-se outras questões do roteiro:

Pesquisador: Na sua opinião, quais são os lugares considerados perigosos em Cuiabá?

Lívia: Paredão, viaduto e... Canjica. Bairro Canjica.

Pesquisador: Por que esses lugares são perigosos?

Lívia: Igual eu falei: o paredão vivem drogados e... Mendigos; no viaduto, como eu já te expliquei, o pai de uma amiga minha já morreu lá... E a gente estava andando com ele, o mais perigoso é que a gente estava andando com ele, aí ele caiu.

Pesquisador: Você viu ele morrer?

Lívia: Hurum.

Pesquisador: Ele caiu do viaduto?

Lívia: Hurum. 
Pesquisador: E você estava junto?

Lívia: Estava perto, eu e a minha amiga. Ele foi buscar a gente na escola, aí ele pegou e caiu.

Pesquisador: Tropeçou?

Lívia: Não. Um cara chegou e empurrou ele com tudo, aí ele caiu.

Pesquisador: Um cara empurrou ele?

Lívia: Hurum.

Pesquisador: E o que vocês fizeram?

Lívia: A gente ficou parado, porque não tinha como, o cara passou com tudo correndo na moto. Na hora que o cara viu que a gente estava... Ele pegou e saiu correndo. Não deu para a gente ver, porque ele estava de capacete.

Pesquisador: Ele empurrou o pai da sua amiga de propósito?

Lívia: Hurum.

Pesquisador: Não foi sem querer?

Lívia: Não foi sem querer.

Pesquisador: Você sabe por quê?

Lívia: Eu não sei explicar isso também, por que ele empurrou. E o Canjica, porque ali só ronda polícia... Só ronda polícia ali, completamente ali por Cuiabá, ali é uma favela. Tiroteio toda hora, bandido matando criança toda hora, estuprador toda hora.

Nesse excerto da entrevista, Lívia revela uma vivência marcante e difícil, que justifica o motivo pelo qual elencou o viaduto como um dos três lugares que não mostraria a um amigo, um lugar que desperta sentimentos de ameaça, perigo e violência e que, por conta de sua vivência da morte do pai da amiga, associa-se diretamente à dimensão topofóbica. Diante disso, quando questionada sobre o que mudaria em Cuiabá para que as pessoas se sentissem mais seguras, Lívia não pensa em muitas alternativas e acaba reforçando Cuiabá como uma cidade perigosa: 
"O policiamento, porque está muito fraco. A segurança... É... E o armamento, porque está muito perigoso aqui em Cuiabá também".

Assim como a cidade, o Centro (que Lívia afirma conhecer) também é considerado um lugar perigoso:

Pesquisador: O que você acha do Centro de Cuiabá?

Lívia: Perigoso também, porque se a gente anda um pouquinho... Ainda mais saída de banco.

Pesquisador: Saída de banco?

Lívia: Hurum. A minha mãe também foi surpreendida, mas graças a Deus devolveram o dinheiro. Esse... É muito perigoso andar no Centro. Traumatiza. Por isso eu falo: "Minha infância foi um pouco ruim e foi um pouco boa". Metade das coisas são muito ruins, a minha infância foi um pouco chata, porque várias coisas que eu vi... Que daí me traumatiza. Até de andar ali na frente do viaduto, eu começo a tremer. E onde eu passo assim... No banco onde minha mãe foi assaltada, eu pego e começo a tremer, a gelar. Então, me traumatiza.

O trecho revela outra vivência desagradável de Lívia, que a traumatiza, para usar o mesmo termo empregado pela menina, em que ela presencia uma situação de violência na cidade, envolvendo sua mãe. Lívia, ao falar de sua infância como algo que já passou, parece não se considerar uma criança, talvez por conta de suas vivências traumatizantes, que, em sua opinião, não deveriam acontecer com crianças de sua idade. Essas mesmas vivências construíram uma relação claramente topofóbica com o viaduto e o banco onde a mãe foi assaltada, de modo que a criança começa a tremer e gelar quando se aproxima desses lugares. O banco, que desperta sentimentos de topofobia, localiza-se no Centro da cidade. Este último, embora remeta à lembrança do assalto (como revela o relato a seguir), não assume caráter topofóbico, uma vez que foi inserido por Lívia no mapa cognitivo (em azul) quando questionada se tinha interesse em fazê-lo. Eis o relato que envolve o Centro: 
Pesquisador: Quando você pensa no Centro de Cuiabá, do que você se lembra?

Lívia: Do assalto que a minha mãe teve e do... E do casamento da minha mãe com o meu pai.

Pesquisador: Por que você lembrou?

Lívia: Porque no... Como fala assim... No assalto, a gente estava dentro do carro. Eu e o meu pai. E no casamento da minha mãe eu estava junto. E daí, eu não aceitei, eu não iria aceitar...

Pesquisador: Por quê?

Lívia: Porque meu pai não é o meu pai. Na verdade, ele só me registrou, mas ele não é o meu pai de sangue. Eu tento procurar meu pai de sangue, mas a minha mãe não deixa.

Pesquisador: Por quê?

Lívia: Porque ela fala que ele não iria se preocupar comigo, que ele não vai ligar para mim.

Pesquisador: Mas você quer conhecer ele?

Lívia: Hurum.

Pesquisador: Nunca viu ele?

Lívia: Não. Só em fotos, mas também não vi o corpo dele inteiro. Só vi ele me segurando. E a minha mãe fala que não: "Não é ele, não é ele, não é ele! É o seu padrasto. Não, não, não!".

As vivências do casamento da mãe e do assalto parecem ganhar destaque no discurso, colocando o Centro em segundo plano, como cenário neutro das situações vivenciadas. Nota-se que Lívia falou de sua família durante toda a entrevista, mas, pela primeira vez, revela que o seu pai, que foi mencionado em vários relatos, não é o biológico. Esse depoimento, aliado à declaração de que Lívia não aceita o casamento da mãe, permite pensar que seus irmãos mais novos são filhos do pai com quem ela convive e que seus conflitos podem estar associados ao sentimento de exclusão e desvalorização, ampliando o sentido da tensão interna já identificada anteriormente. 
Diante dessa interpretação, é possível pensar que, no imaginário de Lívia, sua desvalorização por parte dos pais pode estar associada ao fato de não ser filha biológica do pai presente, e daí surge seu anseio pela procura do pai que ela não conhece. Em outras palavras, Lívia parece pensar que a relação com seu pai biológico de alguma forma estaria associada à valorização de si. Criança e cidade se constroem e reconstroem, em uma constante relação de reciprocidade que se revela em vivências urbanas. Essas vivências permeiam o desenvolvimento infantil, a construção subjetiva e identitária das crianças, revelando a importância da cidade como uma grande sala de aula para a construção da condição cidadã, no exercício de pensá-la e vivê-la em sua dimensão topofílica e seu potencial identitário narrativo.

\section{Considerações finais}

Percebe-se que a relação de Lívia com a cidade é mediada pelos conflitos internos vinculados às vivências dos familiares que, segundo a menina, não têm união por conta dos conflitos. Estes, possivelmente, caracterizam a relação com os irmãos mais novos e são motivo de grande mal-estar, a ponto de levar Lívia à generalização da situação para a relação com toda a família. Nesse contexto, a circulação de Lívia pela cidade, em lugares como a casa dos avós, o Parque Mãe Bonifácia e o Museu do Rio, ganha muita importância por proporcionar momentos agradáveis e de alívio, que parecem diminuir os conflitos.

Nota-se que, mesmo com as vivências traumatizantes como a morte do pai da amiga e o assalto da mãe, reveladoras de sentimentos topofóbicos em relação a lugares como o viaduto, o paredão e o Centro (associado ao banco), Lívia parece pensar a cidade de uma perspectiva edificante, como se as vivências associadas a lugares que provocam sentimentos topofílicos compensassem as vivências traumatizantes associadas à relação com os irmãos e às cenas de violência na cidade. 
Assim, percebe-se que os lugares do afeto permeiam o processo de formação identitária de Lívia e representam a base que lhe permite compensar seus problemas e dificuldades. A casa dos avós, o Parque Mãe Bonifácia e o Museu do Rio são lugares que incitam reações que influenciam a construção subjetiva de Lívia, bem como sua representação socioespacial de Cuiabá. Nesse sentido, a identificação da criança com tais lugares permite não somente pensar a cidade como lugar de pertencimento, mas também pensar a si mesma, nutrindo por Cuiabá a valorização que gostaria que seus pais tivessem por ela. Nesse exercício, a criança recorre à memória social e resgata princípios éticos e valores sociais que revelam a Cuiabá como lugar de pertencimento orientado pelo bem comum, refletindo a importância da valorização das pessoas e da cidade no processo de construção identitária, ou seja, evidenciando que a construção da identidade pessoal está intimamente associada à identidade dos lugares.

\section{Referências}

ALBA, M. Mapas cognitivos: uma ferramenta para a análise de representações socioespaciais. In: SOUZA, C. P. et al. Representações sociais: estudos metodológicos em educação. Curitiba: Champagnat; São Paulo: Fundação Carlos Chagas, 2011. p. 109-149.

CASTORINA, J. A.; KAPLAN, C. V. Las representaciones sociales: problemas teóricos y desafíos educativos. In: CASTORINA, J. A. (Org.). Representaciones sociales: problemas teóricos y conocimientos infantiles. Barcelona: Gedisa, 2003. p. 9-27.

JAMES, A.; JENKS, C.; PROUT, A. Theorizing childhood. Cambridge: Polity Press, 2005.

JODELET, D. As representações sócio-espaciais da cidade. In: DERYCKE, P.-H. (Org.). Concepções de espaço. Paris: Universidade de Paris, 1982. p. 145-177. 
JODELET, D. As representações sociais: um domínio em expansão. In: JODELET, D. (Org.) As representações sociais. Tradução de Lílian Ulup. Rio de Janeiro: EdUERJ, 2001. p. 17-44.

JODELET, D. A cidade e a memória. In: DEL RIO, V.; DUARTE, C. R.; RHEINGANTZ, P. A. (Org.). Projeto de lugar: colaboração entre psicologia, arquitetura e urbanismo. Rio de Janeiro: Contra Capa Livraria, 2002. p. 31-43. (Coleção ProArquitetura).

MOSCOVICI, S. Representações sociais: investigações em psicologia social. Tradução de Pedrinho A. Guareschi. Petrópolis: Vozes, 2003.

TUAN, Yi-Fu. Topofilia: um estudo da percepção, atitudes e valores do meio ambiente. São Paulo: Difel, 1980.

TUAN, Yi-Fu. Espaço e lugar: a perspectiva da experiência. São Paulo: Difel, 1983.

VIGOTSKI, L. S. Imaginação e criação na infância: ensaio psicológico - livro para professores. Apresentação e comentários de Ana Luiza Smolka. Tradução de Zoia Ribeiro Prestes. São Paulo: Ática, 2009.

VIGOTSKI, L. S. Quarta aula: a questão do meio na pedologia. Tradução de Márcia Pilleggi Vinha. Psicologia USP, São Paulo, v. 21, n. 4, p. 681-701, out./dez. 2010.

Recebido: 06/06/2014

Received: 06/06/2014

Aprovado: 15/07/2014 Approved: 07/15/2014 